\section{The 1995 issues}

The 1995 issues have been delayed, and I have appreciated the patience of members and libraries. Now that the May 1995 issue is ready, the November issue is in progress, and the May 1996 issue is likely to be back on schedule.

The November 1995 issue is a special issue on Attention Deficit Hyperactivity Disorder (ADHD) following from the scientific retreat with Professor Russell Barkley organised by the Melbourne-based national executive of the College of Educational and Developmental Psychologists. Particular commendations go to Jennifer Standish and Janine Farrelly for their work on this event.

Members who wish to recommend the issue to other professionals or to clients may wish to photocopy the notice in this issue.

\section{Invitation to comment on the ADHD Special Issue}

Members are invited to write letters to the editor and more detailed professional commentaries, in response to the special issue, for the May 1996 issue. Other manuscripts on $\mathrm{ADHD}$ are also welcome.

\section{Invitation to describe College- approved courses}

Coordinators and convenors of CEDPapproved postgraduate courses are invited to provide an outline of the nature and history of their course (e.g., subjects and rationale for their structure and sequence, key staff, critical references and other resourcing, practicum options and experiences, student numbers, number of graduated cohorts, information on employment of graduates, evaluations of program, etc.). Interesting characteristics of the course program can be highlighted. The way in which core competencies of knowledge, skills, and supervised experience are delivered in the course can be discussed. Manuscripts can be submitted as professional commentary, brief report, or review.

\section{New National Executive}

The College has had a Tasmanian-based national executive from October, 1995. Issues of continuing education, development of core competencies, and examinations for college memebership are under consideration. The Tasmanian Section will continue to function separately.

\section{Draft Policy and Procedures Statement for AEDP}

Australian Educational and Developmental Psychologist is a professional bulletin of The Australian Psychological Society, published for members of the College of Educational and Developmental Psychologists. It publishes peer-reviewed articles and reports that meet the criteria of methodological rigor and psychological relevance. While it is published by the Australian Psychological Society, it maintains editorial independence: Manuscripts are accepted on the basis of their scholarly merit and reflect the professional views of their authors. There is no implication or expectation that these views are endorsed by the Australian Psychological Society. Publication ranges across empirical work, professional analysis, and review. It is the responsibility of the editor of the AEDP to provide opportunity for commentary on professionally significant matters from time to time. A particular effort is made to publish Australian data on development through the lifespan, education in Australian settings, and issues of professional practice by psychologists working in areas of development and education in Australian settings.

Fiona Bryer, Editor 